\title{
RESENHA
}

\section{Sobre etnicidades e infâncias quilombolas}

MATOS, Wesley Santos de; EUGENIO, Benedito. Etnicidades e infâncias quilombolas. Curitiba: CRV, 2019.

\footnotetext{
Alexandre de Oliveira Fernandes Instituto Federal da Bahia, Brasil (iD) https://orcid.org/0000-0002-1556-4373 alexandre.pro@gmail.com
}

O primeiro livro do jovem pesquisador Wesley Santos Matos, "Etnicidades e Infâncias Quilombolas” acaba de ser lançado, resultado de pesquisas realizadas durante seu Mestrado em “Relações Étnicas e Contemporaneidade” na Universidade Estadual do Sudoeste da Bahia - UESB, sob a orientação do professor Benedito Eugenio, que também assina a obra.

Dividido em três partes, o corpo do texto discute conceitos como “comunidades quilombolas”, apresenta os caminhos metodológicos da pesquisa e propõe um "ser quilombola" atravessado por complexa fronteira entre etnicidade, educação e reconhecimento de si. Problematiza a legislação referente à educação quilombola, a exemplo do 
Artigo 26 da Lei de Diretrizes e Bases da Educação - LDB 9394/96 e da Lei 10.639/03, esta votada no primeiro mandato do presidente Luís Inácio Lula da Silva. Delata a invisibilidade dos quilombos no Brasil como efetivamente produzida, ou seja, como um violento projeto de apagamento, sancionado/legalizado por dispositivos diversos - jurídicos, midiáticos e acadêmicos - que consolidaram uma representação perversa: os quilombolas teriam sido extintos, relegados a um passado escravocrata. O que está por detrás disso? A não garantia de direitos e cidadania.

Contam-nos os autores que, se por um lado o aparato normativo atual envidou esforços para descolonizar os currículos, por outro lado, não trouxe qualquer menção às comunidades quilombolas. Trata-se de mais do que um semiocídio ${ }^{1}$, uma violência, pois, para além de exclusão de um vocábulo, a legislação, dúbia e vacilante, não favorece que as políticas educacionais cheguem às comunidades e aos sujeitos para os quais, supostamente, foram pensadas.

Não à toa, discorrem sobre $\mathrm{o}^{*}$ modus operandi *do currículo praticado nas comunidades quilombolas, o qual se interessa mais por apagar as diferenças do que por fortalecer a cultura em que a escola está inserida. Além do que, não se furtam à crítica social e política e nos lembram do menosprezo e do repúdio com que são tratadas as comunidades quilombolas por parte das autoridades e da população branca em geral. Chegam a citar discursos reacionários do então Deputado Federal pelo Estado do Rio de Janeiro, Jair Bolsonaro (PSL - RJ), hoje Presidente da República, denunciando seu desrespeito, a abjeção e o desejo de privar aqueles sujeitos de seus direitos.

O texto de Matos e Eugenio problematiza a forma como se configura o processo de construção do "ser quilombola” entre os moradores de uma comunidade, bem como se ocupa de compreender como práti- 
cas educativas desenvolvidas na escola contribuem para o reconhecimento das crianças enquanto quilombolas. Estas complexas questões implicam a etnicidade como não estanque ou inata, senão produzida, como um discurso, uma tomada de posição política frente a estigmas e marcas distintivas. Talvez, por isso, entreguem ao público um livro que aponta para uma tomada de posição, a saber, aquele momento em que se responde à interpelação discursiva muitas vezes agressiva e estigmatizada, em que um grupo étnico por meio de agrupamentos independentes ou com interesses e reivindicações comuns se organiza e dá origem a movimentos que demandam reconhecimento.

Trata-se então de um estudo delicado acerca da Escola Quilombola "Caminho da Boa Esperança” e da comunidade quilombola "Nova Esperança”, situadas na cidade de Wenceslau Guimarães, Bahia. É de modo respeitoso que os autores nos apresentam a escola e a comunidade, esta certificada pela Fundação Palmares em 2008, resultado de reivindicações e lutas dos moradores. Uma história que se embaraça a Faustino José dos Santos, um dos fundadores do lugar.

Em seu livro, os autores denunciam certo ocaso que a Educação lega às crianças quilombolas quando inseridas em escolas do meio urbano. Ora, e as crianças quilombolas e as crianças negras de zona urbana não têm subjetividades, desejos, interesses diferentes? Mesmo que a fronteira seja tênue, há que se atentar para as diferenças a despeito do Estado que, historicamente, esforça-se por controlar e apagar identidades e diferenças.

Isso não quer dizer que este estudo se apoie em fronteiras étnicas fixas ou numa dicotomia capaz de reforçar etnocentrismos. Sua aposta está no fluxo de pessoas, contudo asseveram que travessias, mesmo que impliquem exclusão e incorporação, não são capazes de derrubar distinções significativas e relações sociais resistentes, haja vista que 
um grupo étnico se reforça exatamente na reafirmação contínua de suas diferenças em relação aos outros.

Matos e Eugenio criticam estudos cujas perspectivas adultocêntricas produziram representações sobre as crianças e a infância, reforçando estereótipos. Apoiando-se em Alan Prout, renomado estudioso da Infância e da Sociologia, nos dão conta de uma visão acadêmica equivocada sobre as crianças e, na contramão, convidam a deslocar o olhar, tornando-nos nós as crianças, sem querer vê-las de fora. É importante adentrar às suas brincadeiras, sentir o mundo com elas, rir com elas, conviver.

Não à toa, o estudo que agora chega às mãos do leitor interessado no assunto, é etnográfico, tendo como técnica a observação participante. Não separa pesquisador e colaboradores, antes, resguarda a excelência da pesquisa, subvertendo o positivismo e sua metodologia clássica. Realizou então, entrevistas com oito crianças, buscando compreender o trabalho executado na escola, o que pensavam sobre si e como concebem a comunidade.

A questão "o que significa ser quilombola” foi lançada a "Beijaflor”, “Andorinha”, "Papa Capim”, “Sete cores”, "Bem-te-vi”, “Coleira” e "Canário”. Também foram convidadas a produzir desenhos que foram analisados a partir de uma abordagem sócio-histórica, ou seja, pautando-se em Márcia Gobbi e Maria Isabel Leite, deu valor ao contexto e às condições de produção dos desenhos. As crianças foram levadas a sério, solapando certo descaso com sua visão de mundo.

O livro nos conta da felicidade das crianças em estar naquela comunidade, sendo marcante sua relação com a natureza e a consciência de serem quilombolas e negras. Outro aspecto destacado é a relação com a família, que tem forte significado para as crianças. A pesquisa, contudo, não romantiza a visão das crianças. Sabe que sua visão do 
ser quilombola está atrelada a características negativas associadas ao negro e a uma sociedade estruturalmente racista, o que afeta, evidentemente, a subjetividade que os indivíduos têm de si.

Ideias como: ser quilombola é "morar na roça”; "trabalhar e ser batalhador”, por um lado apontam para uma leitura factual, empírica, molhada de experiências e, por outro lado, denotam certo esforço dos sujeitos para se diferenciarem do que pregam os discursos hegemônicos, a saber, que negros são preguiçosos, violentos, mau caráter. As falas das crianças dão a ler mais do que o sentimento do indivíduo, haja vista que a experiência (supostamente individual) não se aparta do coletivo e do social, logo, concluem Matos e Eugenio: é motivadora de lutas por reconhecimento.

O estudo aponta que a escola prossegue reforçando estereótipos construídos sobre os negros, atrelando “quilombos” a "passado de sofrimento” e “escravidão”. Não à toa, as crianças podem rejeitar um pertencimento quilombola, haja vista que este se remete a características pesarosas. A escola, entre o consentimento e a ignorância, corrobora com as assimetrias sociais, envida poucos esforços para uma Educação das Relações Étnico-raciais e fomenta práticas racistas.

Segundo Matos e Eugênio, os desenhos coletados durante a pesquisa evidenciaram que as crianças relacionam o ser quilombola com os aspectos raciais. Ora, se a escola reproduz o discurso de que ser quilombola está associado a uma África mítica, escravizada, reforçando estereótipos, nada mais sequencial do que a reelaboração deste discurso pelos estudantes.

Formando a subjetividade das crianças, nessa malha complexa que evoca aquilo que somos (não como um ente ou substância, mas aquilo que está na mediação entre reconhecimento, etnicidade e educação para o estudo ora resenhado), os autores também perceberam uma 
fronteira entre a religiosidade desenvolvida na comunidade e as questões de gênero. Todavia, esta aparece sinalizada nas considerações finais do trabalho, muito mais, parece-me, como um provável desejo de pesquisa futura.

Os autores se apoiaram na antropologia de Fredrick Barth e nos estudos do Direito de André Videira de Figueiredo para conceituar os quilombolas como grupo étnico. De Barth coletam a importância da classificação endógena, ou seja, aquela que os indivíduos tomam para si, em oposição a classificações externas e, de Figueiredo, dando um giro na linha interpretativa tradicional do Direito, entenderam que o grupo étnico é um sujeito coletivo de direitos, o que, para além da salvaguarda jurídica, convoca o Estado a fomentar políticas públicas, práticas e ações que visem à garantia da cidadania.

À Eliane O`Dwyer devem aprofundamento da categoria quilombola como mais do que relativa ao território. Coadunada com certo modo distinto de ser, o "ser quilombola" é aquilo que os diferencia daqueles de fora da comunidade. O pensador Axel Honneth contribui nesse estudo para a compreensão do sujeito coletivo quilombola (ou individuo) como aquele que luta por reconhecimento pleno. Este autor será detidamente discutido ao longo do terceiro capítulo que trata da tese central dos autores - “o ser quilombola” entre a etnicidade, a educação e o reconhecimento de si -, atravessada pela histórica negação dos direitos dessas comunidades.

Logo, este trabalho deve interessar à Sociologia da Infância, à Antropologia, à Educação e aos estudiosos dos Direitos Humanos e das Relações Étnico-raciais, especialmente levando-se em conta que os estudos sobre crianças negras e quilombolas ainda são tímidos, senão marcados por certo rechaço que lega esses sujeitos à invisibilidade inclusive na Academia. Quem se aventurar por "Etnicidades e Infân- 
cias Quilombolas” encontrará uma escrita rigorosa, uma pesquisa generosa e que num momento tão reativo de nosso país, toma partido por comunidades historicamente silenciadas e invisibilizadas. Isto não é nenhum demérito para o livro, ao contrário, aliado dos novos sujeitos (que paradoxalmente sempre estiveram aí) solicita reconhecimento e direitos às comunidades quilombolas. Aí está sua força, exatamente ao se embaraçar ao grupo como uma pesquisa que trabalha desde dentro, sem assepsia e constrangimentos puristas.

Publicado pela editora CRV, equivoca-se apenas em um detalhe, a capa do livro poderia ter sido um dos desenhos das crianças. Ao leitor dessa resenha arrendo o desempate da escolha. 


\title{
Resumo:
}

Trata-se da resenha de Etnicidades e infâncias quilombolas, de Wesley Matos (CRV, 2019).

Palavras-chave: Etnicidades; Infâncias quilombolas; Educação.

\begin{abstract}
:
This is the review of Etnicidades e infâncias quilombolas, by Wesley Matos (CRV, 2019).
\end{abstract}

Keywords: Ethnicities; Quilombola childhoods; Education. 